\title{
Flow resistance of vegetated oblique weir-like obstacles during high water stages
}

\author{
S. Ali and W. S. J. Uijttewaal \\ Environmental Fluid Mechanics Section, Faculty of Civil Engineering and Geosciences, Delft University of Technology, \\ P.O. Box 5048, 2600GA Delft, the Netherlands
}

Correspondence to: S. Ali (s.ali@tudelft.nl)

Received: 19 February 2013 - Published in Hydrol. Earth Syst. Sci. Discuss.: 29 April 2013

Revised: 21 October 2013 - Accepted: 19 November 2013 - Published: 3 January 2014

\begin{abstract}
At high water stages, obstacles (submerged and particularly emerged vegetation) in the flood plains of a river contribute to the flow resistance and hamper the conveyance capacity. In particular the elevated vegetated parts are expected to play an important role. The objective of this research work is to determine the form drag due to vegetated oblique weir-like obstacles. Experiments have been performed to measure the energy head losses for a range of subcritical flow conditions, varying discharges and downstream water levels. The energy head loss caused by the submerged vegetated weir-like obstacle has been modeled using an expansion loss form drag model that has been derived from the one-dimensional momentum conservation equation and accounts for the energy loss associated with a deceleration of the flow downstream of a sudden expansion. The results have been compared with the experimental data and showed an overall good agreement.
\end{abstract}

\section{Introduction}

Water level predictions for extreme events (flood waves) are very important for the design of dykes and embankments and the safety of the area behind them. During extreme discharges, the summer dikes are over-topped and a part of the river discharge flows through the winter bed with several obstacles. The winter bed contains vegetation as well as weirlike obstacles such as access roads (elevated), summer embankments, submerged groynes, etc. These obstacles affect the flow levels during floods, especially in cases with vegetated areas on them. Understanding of flow characteristics concerning summer dikes and vegetated weir-like obstacles can be helpful for river managers. These weir-like obstacles can be perpendicular or at an angle to the flow direction. The characteristics and hydraulic behavior of plain or standard weirs have been studied for a long time and the knowledge on them is rather profound (see e.g. Chow, 1959). However, a few studies have been done on weirs placed obliquely in the flow. The most important difference between an oblique weir and a plain weir is that the crest of the oblique weir makes an angle with the flow direction in the channel. An extreme example is the side weir, a part of the channel embankment, whose crest is parallel to the flow direction in the channel (Bos, 1989). Its function is to drain water from the channel whenever the water surface rises above a predetermined level so that the channel water surface downstream of the weir remains below a maximum permissible level. Aichel (1953) presented a new relation for the discharge coefficient of a round crested skewed-weir compared with the plain weir. De Vries (1959) also did many experiments to examine the energy loss of the flow over dike-form weirs under different oblique angles and flow conditions. The main objective of his research was to examine the influence of the obliqueness of the weir to the stage-discharge relation and the experiments were done on trapezoidal weirs. Borghei et al. (2003) derived a relation for the discharge coefficient for oblique rectangular sharp-crested weirs based on experimental data. Borghei et al. (2006) improved the previous formula for the discharge coefficient for oblique sharp crested weirs by using the incomplete self-similarity (ISS) concept. Borghei's formula is an empirical relation and is only applicable for the sharp crested plate-type weirs and is not useful for the trapezoidal weirs. Wols et al. (2006) published the numerical simulations of oblique weirs using a non-hydrostatic finite 


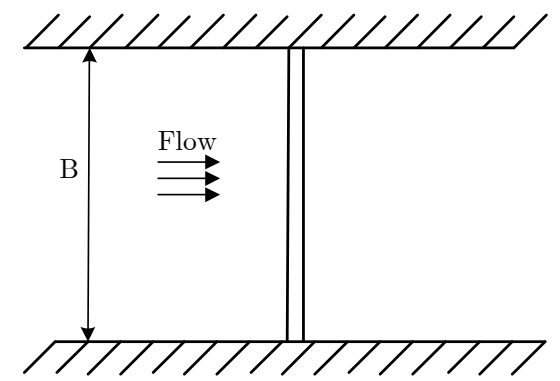

(a). Top view of a plain weir

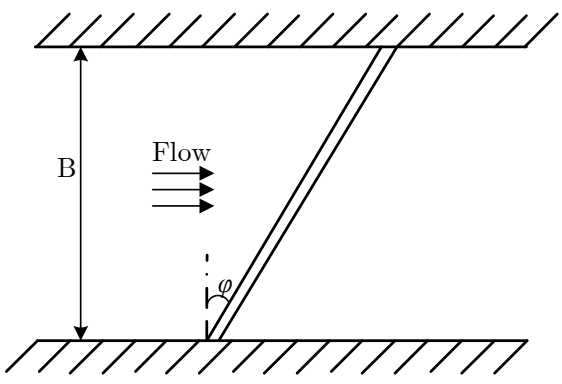

(b). Top view of an oblique weir

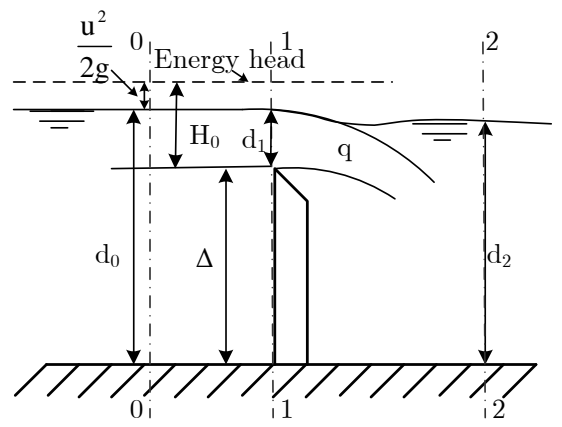

(c). Side view of a sharp crested weir

Fig. 1. Plane and side views of the weirs.

elements model FINLAB. Wols et al. (2006) investigated that the model could reproduce the bulk parameters like discharge coefficients and the energy head losses due to the trapezoidal weir, however the flow field in the recirculation zone of the weir was represented incorrectly. Tuyen $(2006,2007)$ measured the energy head loss and discharge coefficients for different trapezoidal weir configurations (for $0,30,45$ and $60^{\circ}$ angle of obliqueness) and flow conditions. Ali and Uijttewaal $(2009,2010)$ studied the vegetated weir-like structures oriented perpendicular to the flow direction and quantified the energy head loss caused by such types of obstacles. An expansion loss form drag model was developed to estimate the energy head losses.

The main goal of this research is to determine the energy head loss due to the oblique, vegetated weir-like structures (rigid and cylindrical vegetation) and to describe the structure of the flow phenomena related to it. The present study will also examine the physical processes which play a role.

\section{Definitions}

The following terms are used throughout the paper for the flow conditions.

- Hydraulic jump: the rise in water level, which occurs during the transformation of supercritical flow to subcritical flow, is called hydraulic jump (standing wave).

- Free-flow (perfect weir) conditions: free flow (unsubmerged flow) over a weir exists when the downstream water surface is at or below the crest of the weir (Froude number is 1).

- Submerged-flow (imperfect weir) conditions: submerged weir flow exists when the downstream water surface is above the crest of the weir (Froude number above the crest $<1$ ).

\section{To determine the discharge over a weir}

There is an extensive knowledge on the perpendicular (plain) sharp crested weir in the literature, such as Rehbock (1929), Rouse (1936), Kindsvater and Carter (1957), Kandaswamy and Rouse (1957), Ramamurarthy et al. (1987), Swamee (1988), Hager (1984, 1993), Munson et al. (2002), Azimi and Rajaratnam (2009), which is summarized in standard text books such as Bos (1989) and Chow (1959). Flow properties for an embankment broad crested weir has been discussed by Fritz and Hager (1998) and Sargison and Percy (2009).

Figure 1 shows the configurations for flow over a sharp crested weir. With the elementary analysis for a plain weir placed normal to the flow direction, the discharge relation in case of the free-flow conditions is

$q_{0}=\frac{2}{3} C_{\mathrm{df}} \sqrt{\frac{2}{3}} g H_{0}^{\frac{3}{2}}$,

where $q_{0}\left(\mathrm{~m}^{3} \mathrm{~s}^{-1} \mathrm{~m}^{-1}\right)$ is the specific discharge (discharge per unit length), $C_{\mathrm{df}}$ is the discharge coefficient for free-flow conditions, $g\left(\mathrm{~m} \mathrm{~s}^{-2}\right)$ is the gravitational acceleration and $H_{0}$ 
(m) is the energy head (Bos, 1989). Using the energy balance on the upstream side of the weir (Fig. 1), the discharge coefficient $C_{\mathrm{df}}$ is written as (Wols et al., 2006)

$C_{\mathrm{df}}=\frac{3 \sqrt{3} F r_{1}}{\left(2+F r_{1}^{2}\right)^{3 / 2}}$

where $F r_{1}\left(F r_{1}=\frac{u_{1}}{\sqrt{g d_{1}}}\right)$ is the Froude number above the weir crest, $d_{1}(\mathrm{~m})$ is the water depth and $u_{1}\left(\mathrm{~m} \mathrm{~s}^{-1}\right)$ is the average velocity above the weir crest.

Depending on the downstream water depth, the weir could be in a submerged or free-flow condition. The general relation for the submerged specific discharge $(q)$ of a plain weir is

$q=C_{\mathrm{d}} q_{0}$,

$q=C_{\mathrm{df}} C_{\mathrm{d}} \frac{2}{3} \sqrt{\frac{2}{3}} g H_{0}^{\frac{3}{2}}=C \frac{2}{3} \sqrt{\frac{2}{3}} g H_{0}^{\frac{3}{2}}$,

where $C_{\mathrm{d}}$ is the discharge reduction coefficient and $C=C_{\mathrm{df}} C_{\mathrm{d}}$ is the discharge coefficient. Villemonte (1947), Govinda Rao and Muralidhar (1963), Brater and King (1976) and Wu and Rajaratnam (1996) introduced the discharge reduction coefficient $C_{\mathrm{d}}$ for sharp crested weirs and Fritz and Hager (1998) for the embankment weir with side slopes of $1: 2$ as a function of submergence $(S)=H_{2} / H_{0}$. Here $H_{2}(\mathrm{~m})$ is the downstream energy head.

The discharge reduction coefficient $\left(C_{\mathrm{d}}\right)$ due to submergence for sharp crested weirs was given by the empirical relation of Villemonte (1947):

$C_{\mathrm{d}}=\left(1-S^{1.5}\right)^{0.385}$

The more general form for this relation which is used in practice is

$C_{\mathrm{d}}=\sqrt{\left(1-S^{P}\right)}$

where $P$ is an empirical co-efficient which is influenced by the weir geometry.

The geometrical feature of an oblique weir enhances the efficiency of the weir, increasing the effective weir length ( $L=B / \cos \varphi$ ) and hence increasing the discharge for the same water head and the same channel width.

The concept of drag/discharge coefficients is fully empirical. Aichel (1953) related the specific discharge $\left(q_{\mathrm{L}}\right)$ for an oblique weir (based on the crest length) to the specific discharge of a perpendicular weir $(q)$ in the following way

$\frac{q_{\mathrm{L}}}{q}=1-\beta_{\mathrm{A}} \frac{d_{0}-\Delta}{\Delta}$,

where $d_{0}(\mathrm{~m})$ is the water depth upstream of the weir, $\Delta$ is the weir height and $\beta_{\mathrm{A}}$ is the coefficient depending on the angle of obliqueness. This coefficient increases with the angle of obliqueness (Fig. 2) and the specific discharge decreases.

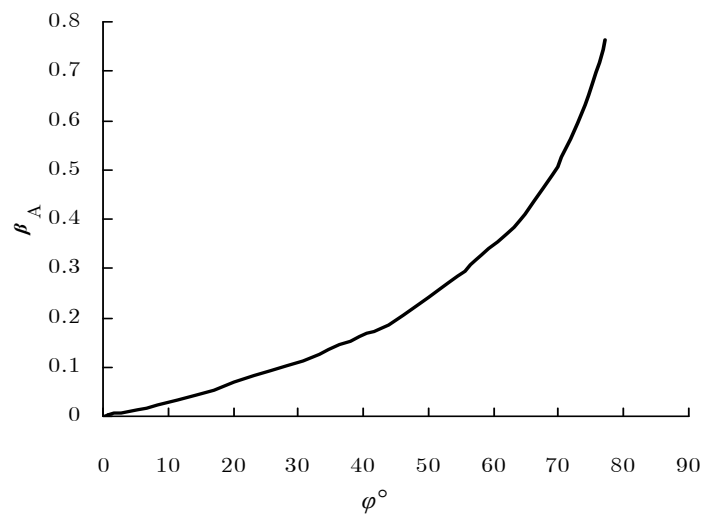

Fig. 2. $\beta_{\mathrm{A}}$ values as a function of the angle of obliqueness $\left(\varphi^{\circ}\right)$ (Bos, 1989).

Borghei et al. (2003) derived the following empirical expression for the discharge coefficient for the perfect weir (freeflow conditions) based on experimental data:

$C_{\mathrm{df}}=\left(0.701-0.121 \frac{B}{L}\right)+\left(2.229 \frac{B}{L}-1.663\right) \frac{\left(d_{0}-\Delta\right)}{\Delta}$,

where $B(\mathrm{~m})$ is the width of channel and $L(\mathrm{~m})$ is the length of the weir. For an imperfect weir (submerged flow) $C_{\mathrm{df}}$ is multiplied by a factor $C_{\mathrm{d}}$ depending on the submergence of the weir $\left(\frac{d_{2}-\Delta}{d_{0}-\Delta}\right)$ as follows

$C_{\mathrm{d}}=\left[\left(0.008 \frac{L}{B}+0.985\right)+\left(0.161 \frac{L}{B}-0.479\right)\left(\frac{d_{2}-\Delta}{d_{0}-\Delta}\right)^{3}\right]^{2}$,

where $d_{2}(\mathrm{~m})$ is the water depth on the downstream side of weir. The discharge reduction coefficient $\left(C_{\mathrm{d}}\right)$ increases with the angle of obliqueness as well as the discharge.

\section{Mathematical formulation (analytical approach)}

The theoretical analyses of weirs are important for the prediction and interpretation of experimental data. The effect of vegetated obstacles on the flow can be considered to either induce an energy loss or exert a drag force on the flow. Yalin (1964) and Engelund (1966) assumed that the effect of bed forms on the flow is analogous to a sudden expansion in a pipe flow. The energy loss due to a sudden pipe flow expansion is calculated using the one-dimensional (1-D) linear momentum and energy conservation equations. Karim (1999) and van der Mark (2009) considered the effects of bed form on flow as sudden expansion for the open channel flow instead of a pipe flow. Ali and Uijttewaal $(2009,2010)$ also studied the vegetated weir-like structures oriented perpendicular to the flow direction to quantify the energy head loss. To determine flow velocity and water depth around the weir-like structure, such as a submerged groyne or a spur dike, the following assumptions can be made (see Fig. 3). 


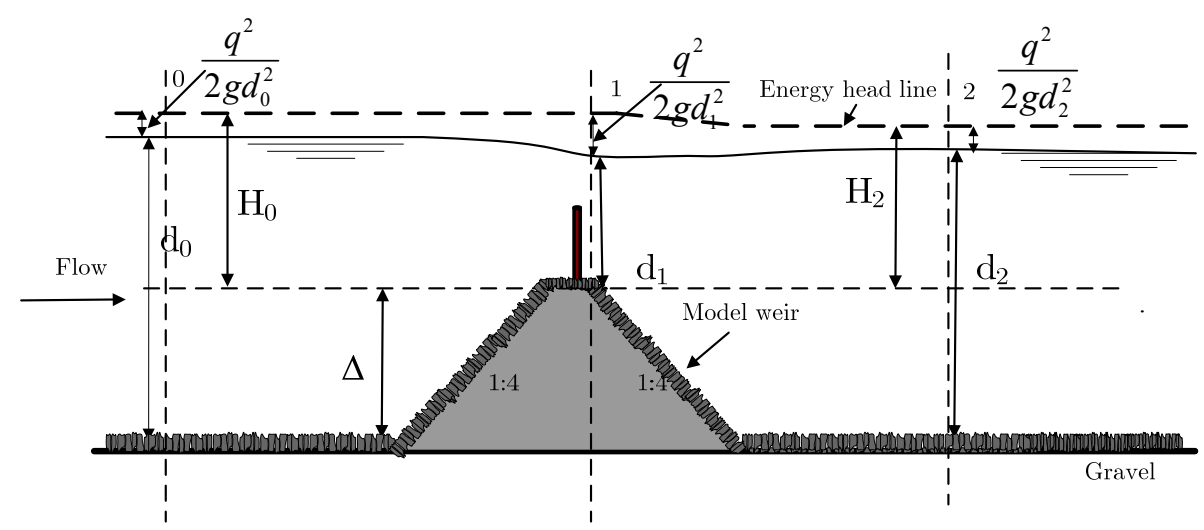

Fig. 3. Side-view of the vegetated oblique weir and flow over the weir with rough surfaces.

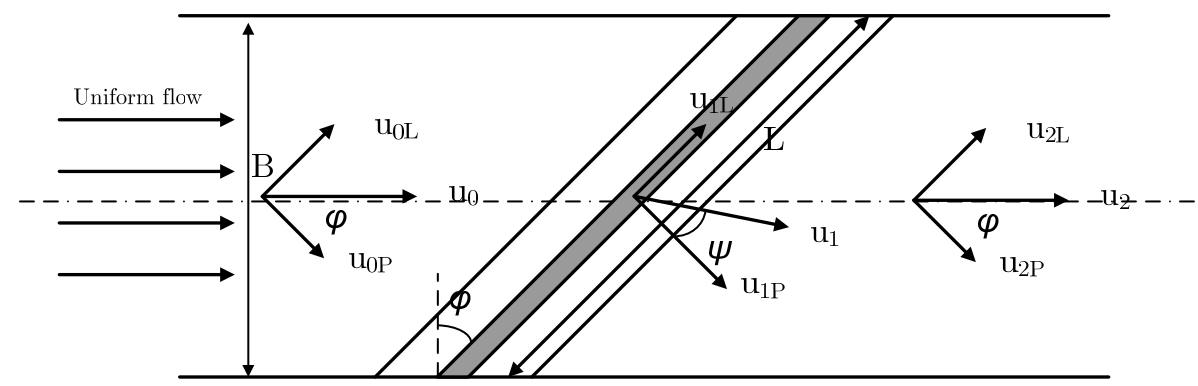

Fig. 4. Velocity decomposition upstream, at the crest and downstream of an oblique weir.

- Energy is conserved over the upstream face of the groyne or spur dike (between section 0 and 1).

- Momentum is conserved at the downstream side of the groyne (between section 1 and 2).

At the upstream side the streamlines are contracting and energy is conserved where as at the downstream side, there is a sudden expansion and energy is dissipated in this region. On the downstream side, the momentum conservation equation in a longitudinal $(x)$ direction has been applied. The continuity (the conservation of the water mass) is valid in the domain considered in this study. It is assumed here that the flow is steady, frictionless and incompressible and the pressure distribution above the weir crest is hydrostatic.

For a weir inclined to the flow, the flow velocity could be decomposed into two components, parallel and perpendicular to the flume axis, it can also be decomposed into two components parallel and perpendicular to the weir axis (Fig. 4). Theoretically, it is assumed that the crest parallel component does not change its magnitude, when the flow reaches the weir. The accelerating force only acts on the velocity component perpendicular to the weir crest and the same holds for the deceleration process. The angle of flow obliqueness is the deviation angle of the stream lines from the normal direction with respect to the weir crest. For the plain weir this angle is zero. For an oblique weir value of flow direction $(\psi)$ above the weir crest can be predicted using an energy balance and the continuity requirement for the flow.

The dimensionless energy conservation (using the perpendicular component of the velocity) for an oblique weir between section 0 and 1 is written as

$d_{0}^{* 3}-\left(d_{1}^{*}+\Delta^{*}+\alpha_{1} \frac{1}{2 d_{1}^{* 2}}\right) d_{0}^{* 2}+\frac{1}{2} \alpha_{0}=0$,

where $d_{0}, d_{1}, d_{2}$ are water depths, $\Delta$ is the weir height, $g$ is the gravitational acceleration, $\alpha$ is the kinetic energy correction coefficients and $u_{0}, u_{1}, u_{2}$ are the depth averaged velocities at sections $0,1,2$, respectively. ${ }^{*}$ represents the length scales made dimensionless using the critical depth above the weir crest. The derivation of this equation is given in the Appendix A. If the value of $d_{1}^{*}$ is known, $d_{0}^{*}$ can be found as a root of the Eq. (6).

At the downstream side of weir, energy is dissipated in the wake region due to the deceleration of the flow. The dimensionless momentum conservation perpendicular to the weir crest, assuming a hydrostatic pressure distribution and ideal flow (no friction losses) applied to sections 1 and 2 yields:

$d_{1}^{* 3}+2 \Delta^{*} d_{1}^{* 2}+\left(\Delta^{* 2}-d_{2}^{* 2}-\beta_{2} \frac{2}{d_{2}^{*}}\right) d_{1}^{*}+2 \beta_{1}=0$,

where $\beta$ is the dimensionless momentum correction coefficient. If the value of $d_{2}^{*}$ is known, $d_{1}^{*}$ can be found from 
a).

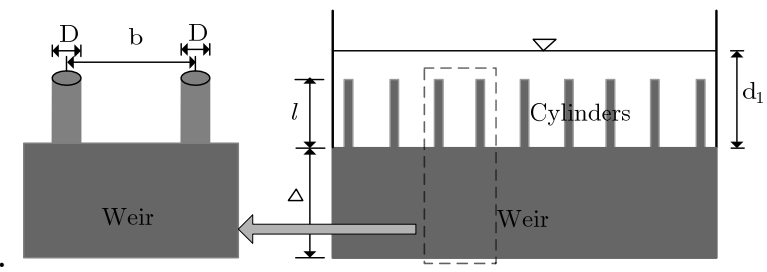

b).

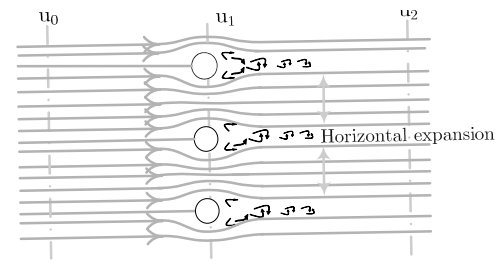

Fig. 5. (a) Cross section of weir with vegetation roughness at Sect. 1; (b) flow around the cylindrical rods on the weir crest (Top view).

Eq. (7). For natural channels, the correction factors $(\alpha$ and $\beta)$ vary between $1.15-1.50$ and $1.05-1.17$, respectively. (Chow, 1959; Chaudhry, 1994).

\subsection{Flow direction and oblique angle}

A relation between the angle of obliqueness $(\varphi)$, the flow direction $(\psi)$ above the weir crest and flow conditions is given below (see Fig. 4).

$\frac{\tan \psi}{\tan \varphi}=\left(\frac{F r_{0 \mathrm{p}}}{F r_{1 \mathrm{p}}}\right)^{\frac{2}{3}}$

This equation is derived in the Appendix B. The flow direction can be calculated above the weir crest using Eq. (8). As the velocity increases on the weir crest, the flow approaches a direction normal to the weir crest. For free-flow conditions the flow is directed virtually perpendicular to the weir crest.

\subsection{Weir with vegetation}

\subsubsection{Emerged vegetation}

In this case the weir has a row of cylinders on the top of its crest which represents the stem type of vegetation (mature trees without foliage in the lower sections) which causes extra energy losses. Energy dissipation in this case is caused by different processes. First, the wakes downstream of the stems and recirculation downstream of the weir both contribute to the head loss. Second, there is an interaction between the wake turbulence generated by the weir and by the vegetation. Here the latter interactions have been ignored. The effect of vegetation on the cross-sectional area is considered and the depth averaged velocity is calculated in this section with reduced cross-sectional area (vegetation cross-sectional contraction and weir effect) (Ali and Uijttewaal, 2013). The velocities at the three cross sections in Fig. 3 can be written as

$u_{0 \mathrm{p}}=\frac{q_{\mathrm{L}}}{d_{0}} u_{1 \mathrm{p}}=\frac{q_{\mathrm{L}} b}{d_{1}(b-D)}=\frac{q_{\mathrm{L}}}{d_{1}}\left(\frac{1}{1-\frac{D}{b}}\right) u_{2 \mathrm{p}}=\frac{q_{\mathrm{L}}}{d_{2}}$.

Here $b$ is the centre to centre distance between two adjacent cylinders and $D$ is the diameter of a cylinder as shown in Fig. 5. The critical flow depth establishes where the cross section is minimized between the rods on the weir crest and is given by $d_{1 \mathrm{cr}}^{3}(1-D / b)^{3}=\frac{q_{\mathrm{L}}^{2}}{g}$.

The non-dimensionalized (using the critical depth) energy and momentum conservation can then be written as

$$
\begin{aligned}
& d_{0}^{*}+\alpha_{0} \frac{1}{2 d_{0}^{* 2}}=\Delta^{*}+d_{1}^{*}+\alpha_{1} \frac{1}{2 d_{1}^{* 2}}\left(\frac{1}{1-\frac{D}{b}}\right)^{2} \\
& \left(\Delta^{*}+d_{1}^{*}\right)^{2}+\beta_{1} \frac{2}{d_{1}^{*}}\left(\frac{1}{1-\frac{D}{b}}\right)=d_{2}^{* 2}+\beta_{2} \frac{2}{d_{2}^{*}} .
\end{aligned}
$$

\subsubsection{Submerged vegetation}

In this case the water level exceeds the height of cylinders as shown in Fig. 5. The dimensionless energy conservation and momentum conservation between section 0 and 1 and section 1 and 2 respectively can be written as

$$
\begin{aligned}
& d_{0}^{*}+\alpha_{0} \frac{1}{2 d_{0}^{* 2}}=\Delta^{*}+d_{1}^{*}+\alpha_{1} \frac{1}{2 d_{1}^{* 2}}\left(\frac{1}{1-\frac{l^{*} D}{d_{1}^{*} b}}\right)^{2} \\
& \left(\Delta^{*}+d_{1}^{*}\right)^{2}+\beta_{1} \frac{2}{d_{1}^{*}}\left(\frac{1}{1-\frac{l^{*} D}{d_{1}^{*} b}}\right)=d_{2}^{* 2}+\beta_{2} \frac{2}{d_{2}^{*}},
\end{aligned}
$$

where $l^{*}$ is defined as the dimensionless vegetation height. By knowing the downstream water depth and the specific discharge, the upstream water depth and the energy head $\left(H_{0}\right)$ can be determined using this analytical approach. Subsequently the discharge coefficient can be determined according to Eq. (3).

\subsubsection{Bed and wall resistance}

The total energy head loss $\left(\Delta H_{\mathrm{t}}\right)$ in a flume over a distance $L_{\mathrm{e}}$ can be due to the following three sources as explained by Ali and Uijttewaal (2013);

- form drag due to obstacles $(\Delta H)$,

- Grain and skin friction of the bed $\left(\Delta H_{\mathrm{B}}\right)$,

- the side wall friction $\left(\Delta H_{\mathrm{W}}\right)$. 
The energy losses due to the bed and friction of two side walls can be obtained as

$\Delta H_{\mathrm{B}}=c_{\mathrm{f} 2} \int_{0}^{L_{\mathrm{e}}}{\frac{u^{2}}{g d}}^{2} d \ell, \Delta H_{\mathrm{W}}=c_{\mathrm{f} 3} \int_{0}^{L_{\mathrm{e}}}{\frac{2 u^{2}}{g B}}^{2} d \ell$,

where $L_{\mathrm{e}}$ is the length between the section 0 and $2, B$ is the flume width, $d$ is water depth and $u$ is average velocity. The friction coefficient $\left(c_{\mathrm{f}}\right)$ and friction factor $(f)$ can be related as $c_{\mathrm{f}}=\frac{f}{8}$. The friction factor is calculated by the Colebrook-White formula (Colebrook, 1939). To compare the experimental data with the analytical results, these estimated energy losses (caused by the bed and wall friction) are deducted from the total energy head loss to get the energy loss of the vegetated weir-like obstacle.

$\Delta H=\Delta H_{\mathrm{t}}-\Delta H_{\mathrm{B}}-\Delta H_{\mathrm{W}}$

\subsection{Evaluation of analytical model}

\subsubsection{Flow direction over the weir}

Figure 6 shows the variation of the stream line angle over the oblique weir against the water depth above the weir crest for different inclinations. These graphs are plotted using Eqs. (B1), (B2) and (8). Figure 6a-c are for different dimensionless weir heights. Using a constant discharge implies that the weir height is constant with respect to the critical depth. In a critical flow condition $\left(d_{1}^{*}=1\right)$, the water has the highest velocity and thus is most sensitive to the effect of weir. Increasing the water depth gives a submerged weir flow condition and tends toward an unaffected flow direction for large values $d_{1}$ especially for a low weir (e.g $\left.\Delta^{*}=0.5\right)$. With a high weir the upstream velocity is low so the velocity above the weir is mainly due to the weir and thus almost perpendicular $\psi \rightarrow 0$.

\subsubsection{Energy head loss}

Figure 7a shows the variation of energy head loss against the Froude number on the weir crest for different weir heights (with $\alpha=1$ and $\beta=1$ ). It is seen that in all cases the energy head loss tends to zero when $F r_{1}$ goes to zero. The value of $H_{2} / H_{0}=1$ is not affected by the inclination of the weir because $H_{0}$ is compared to $H_{2}$ and both are defined in the same way. At the critical flow condition $\left(F r_{1}=1\right)$ the upstream water level becomes independent of the downstream water level.

As it is assumed that only the velocity component perpendicular to the weir is changed, using the energy and momentum conservation laws perpendicular to the weir crest, we get a weak dependence of the energy head loss on the weir inclination to the flow direction. This shows as a smaller head loss at higher inclination angles apparently because the larger inclination results in a smaller velocity component perpendicular to the weir and a subsequent smaller acceleration/deceleration cycle.

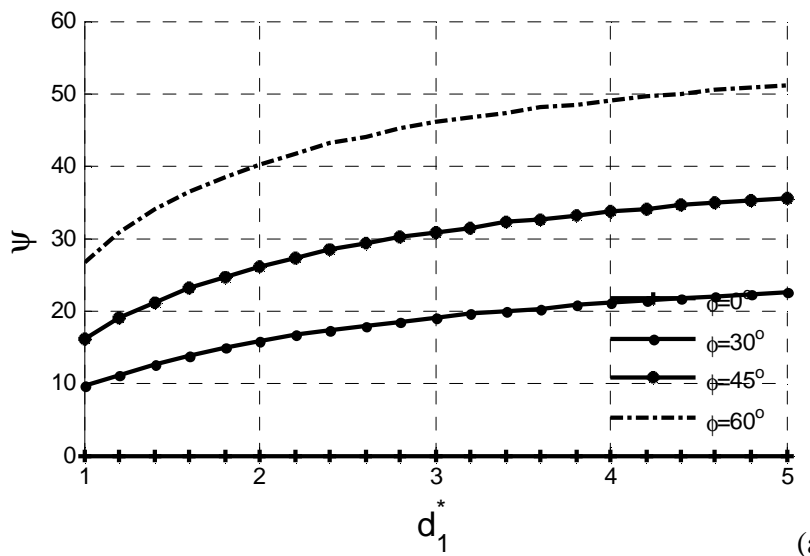

(a)

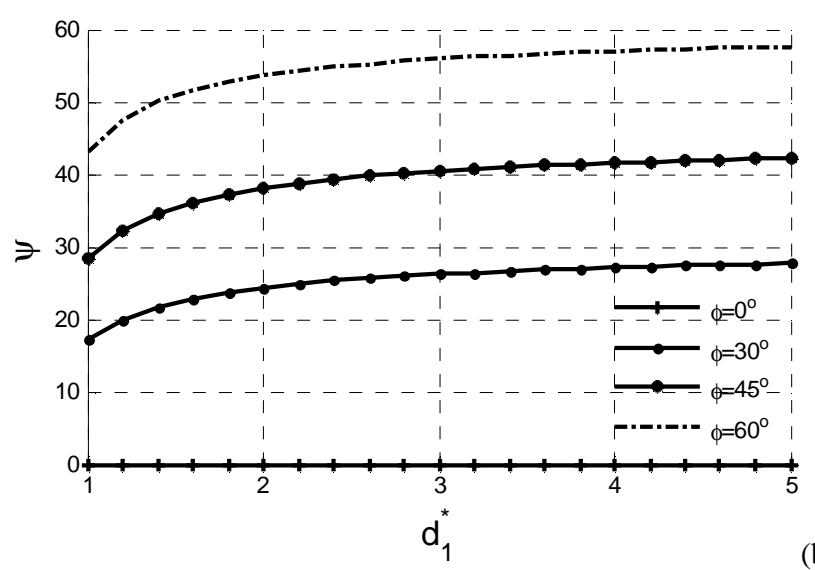

(b)

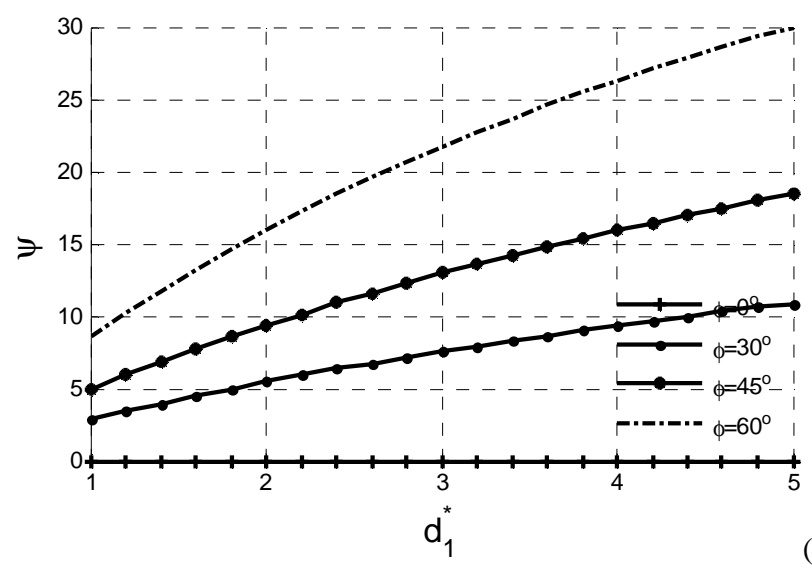

(c)

Fig. 6. Flow direction on the weir crest versus water level on the weir crest (a) $\Delta^{*}$ (Dimensionless weir height) $=0.5$, (b) $\Delta^{*}=2$, (c) $\Delta^{*}=10$.

Figure $7 \mathrm{~b}$ shows the variation of discharge coefficient against $\mathrm{H}_{2} / \mathrm{H}_{0}$. The discharge coefficient $C$ tends to one for small values of $H_{2} / H_{0}$. For low downstream water levels, the flow conditions over the weir crest become critical and result in a constant discharge coefficient. Here a problem arises with the definition of $H_{0}$. If one accounts for the total velocity head, the discharge is overestimated since only 


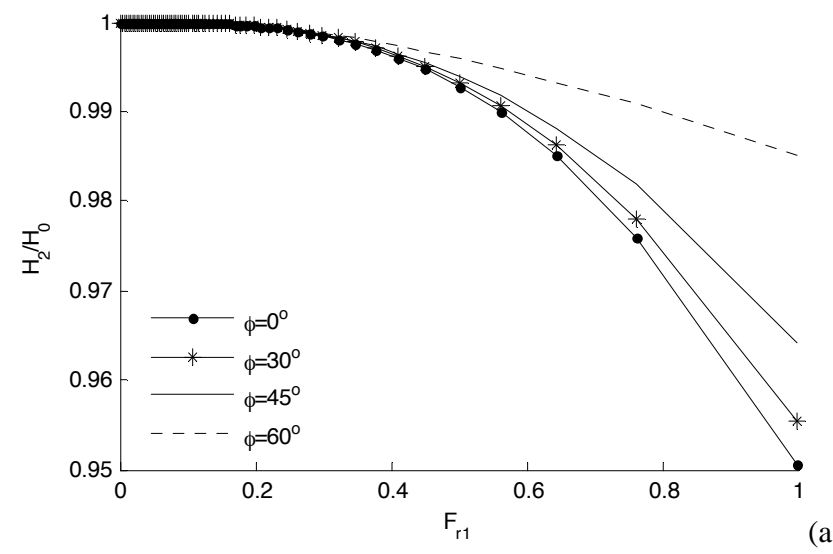

(a)

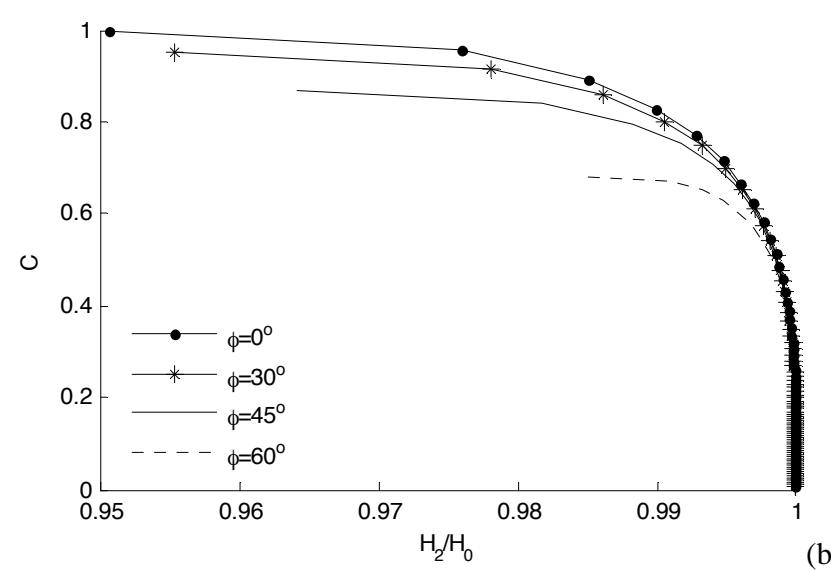

(b)

Fig. 7. Variation of energy head loss against the Froude no. on the weir-crest (a), Variation of discharge coefficient against the energy head loss $(\mathbf{b})$, for $\Delta^{*}=0.5$.

the velocity component perpendicular to the weir contributes to the discharge. This is especially important for low weirs where the upstream velocity has a relative large contribution to $H_{0}$.

\subsubsection{Comparison with Borghei et al. (2003)}

A comparison is made between our analytical approach and the empirical approximation by Borghei et al. (2003) as given in Sect. 2. It should be noted that for the submerged weir case the downstream configuration of the flow domain determines the further direction of the streamlines. The presented results therefore only hold for the specific configuration used by Borghei et al. (2003).

For this case, we consider the perpendicular component of the velocity with respect to the weir, it could straightforwardly be treated as a standard submerged weir. Their analysis only seems to make sense for small values of $H_{0} / \Delta$ in that case the potential head is dominant over the velocity head and $\left(d_{0}-\Delta\right) / \Delta$ is approximately equal to $H_{0} / \Delta$. For the oblique weir the definition of $H_{0}$ does not correspond to the definition of $C_{\mathrm{df}}$ which becomes increasingly apparent for higher
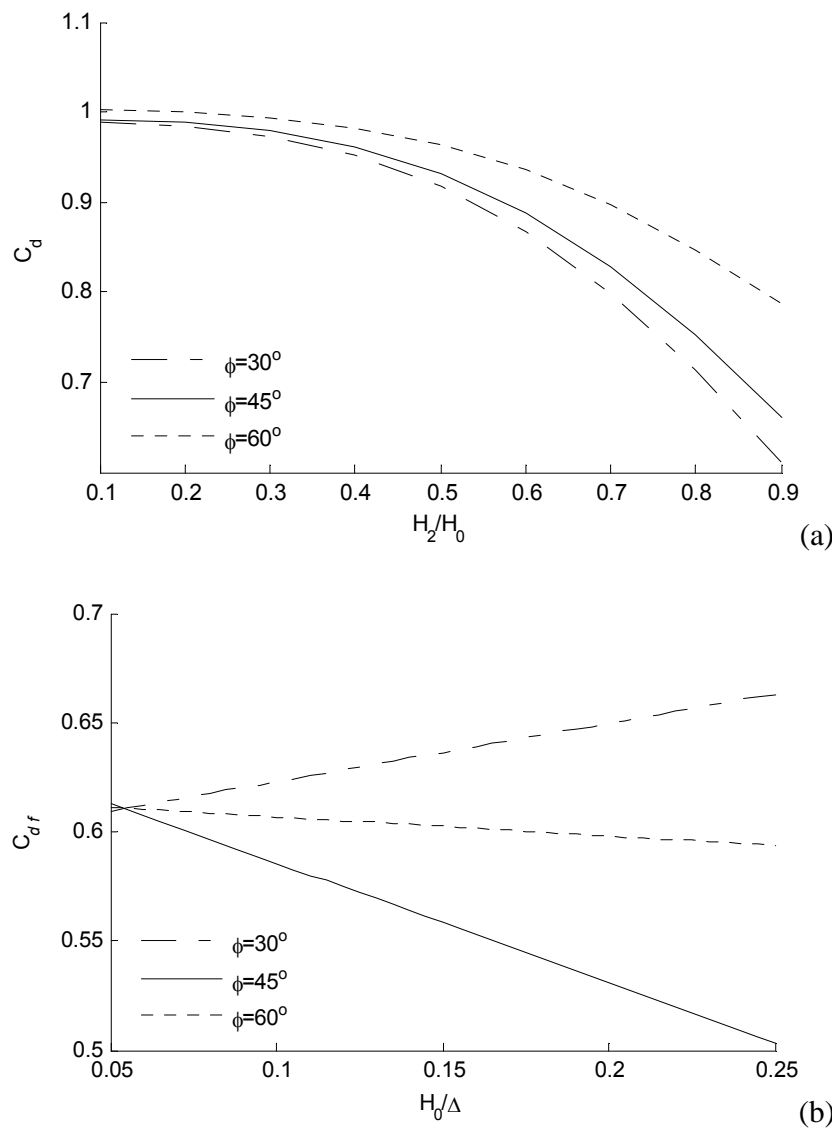

(b)

Fig. 8. Discharge coefficient variation according to Borghei et al. (2003), (a) discharge reduction coefficient for imperfect weir $\left(C_{\mathrm{d}}\right),(\mathbf{b})$ and free-flow discharge coefficient $\left(C_{\mathrm{df}}\right)$.

values of $d / \Delta$. For that reason it is not strange that the $C_{\mathrm{df}}$ value varies. The definition of $C_{\mathrm{d}}$ is a bit simpler. The graph (Fig. 8) shows the effect that a larger inclination leads to a smaller loss.

\section{Experiments}

In order to perform the experiments that are representative for the processes on a prototype scale, requirements regarding the Froude number and Reynolds number have to be fulfilled. To this end the prototype conditions are schematized and down scaled approximately $1: 75$. Doing so, a Froude number scaling was achieved. The low Reynolds number is not considered a problem as long as the flow is fully turbulent.

\subsection{Experimental setup}

The experiments were conducted in a rectangular horizontal glass flume, $19.2 \mathrm{~m}$ long, $2 \mathrm{~m}$ wide and $22 \mathrm{~cm}$ deep. An oblique weir was situated (approximately) in the middle of the flume. To represent the hydraulically rough floodplain, 


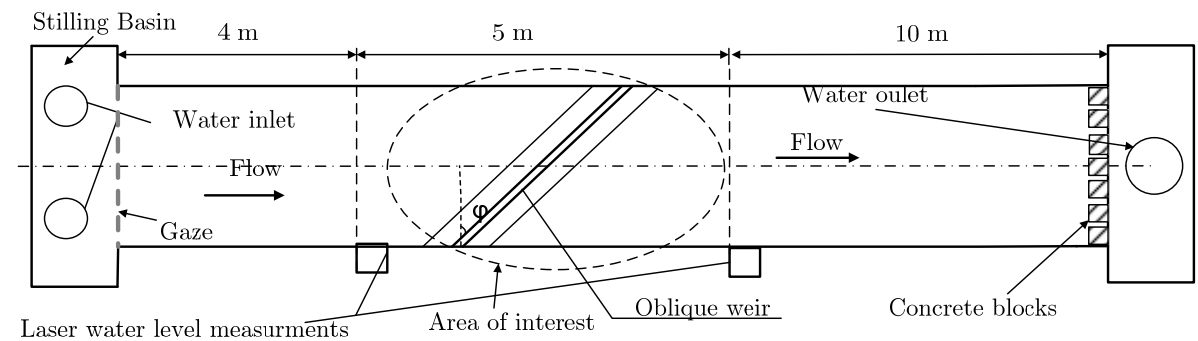

Fig. 9. Schematized plane view of the flume and measuring apparatus.
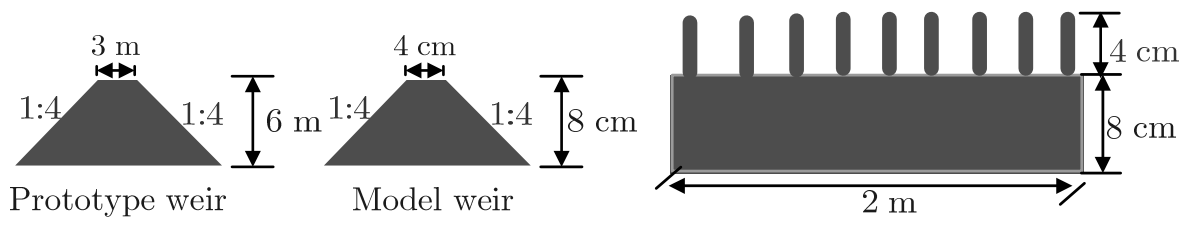

Frontal view of the vegetated weir

Fig. 10. Prototype dyke and model weir (scaled $1: 75$ ).

gravel of diameter 5 to $8 \mathrm{~mm}$ was glued on the flume bed and over the weir surface. The angle of obliqueness of the weir is $45^{\circ}$. The flow from a $250 \mathrm{~mm}$ conduit was discharged into a stilling basin and then into the experimental flume. Discharge of water to the flume was measured by an electromagnetic flow metre mounted on the conduit (Fig. 9).

For this study a prototype trapezoidal dike of height $6 \mathrm{~m}$ with a crest width $3 \mathrm{~m}$ and the side slopes $1: 4$ (both, upstream and downstream side) was used. The model was made of composite, wood and concrete material. The oblique model weir had a height of $8 \mathrm{~cm}$ (crest width $4 \mathrm{~cm}$, scale $1: 75$ ) with the upstream and downstream slopes of $1: 4$. The stem type rigid vegetation on the weir crest was modeled by circular cylinders. The relative vegetation blockage on the weir crest was $25 \%$. The height of the model plants was $4 \mathrm{~cm}$ and the diameter was $1.2 \mathrm{~cm}$ (Fig. 10).

\subsection{Measuring equipment}

Point gauges were used to measure the flow depth at the centre of weir crest. To measure the water depths first the elevation of the water surface and then the elevation of the bed at that point was measured. To get the value of flow depth, the later was subtracted from the first. There were two point gauges mounted on a moveable beam in such a way that the measurement could be made across the flume. The beam itself was mounted on the flume on two side rails. The height of the free surface and the bed level were measured with an accuracy of $\pm 0.2 \mathrm{~mm}$.

For supercritical flows, the water surface was highly unstable behind the weir due to undulations and hydraulic jumps and sometimes due to air entrainment. These aspects together decreased the accuracy of water level determination to $\pm 1 \mathrm{~mm}$. Far downstream of the weir, the flow surface calmed down and the accuracy of the depth measurement could be considered as normal $( \pm 0.2 \mathrm{~mm})$.

Laser displacement sensors (ILD1300) were used to measure the water depth $2 \mathrm{~m}$ (from centre of the weir) upstream and $3 \mathrm{~m}$ down stream of the weir. It is an optical sensor for measurements with an accuracy of $\pm 0.2 \mathrm{~mm}$.

The acoustic Doppler velocimeter (ADV) Vectrino was used to measure the (3-D velocity components) velocity profiles at different locations in the vicinity of the weir.

\subsection{Experimental programme}

Tests were carried out (for an oblique weir) for several discharge conditions by varying the discharge and downstream water level. The inflow was provided with the discharge of $20,25,30,35,40 \mathrm{~L} \mathrm{~s}^{-1}$. For each discharge the downstream water depth was adjusted and gradually varied to give the 15 different flow states, from completely sub-merged to the free-flow regime. After adjustment, almost 10 min were required to stabilize the flow after which the water depth measurements were performed. The different cases for an oblique weir $\left(\varphi=45^{\circ}\right)$ with a down stream slope of $1: 4$ were

- weir without vegetation roughness, and

- weir with vegetation roughness (25\% blockage area).

For these measurements the dimensionless weir height $\left(\Delta^{*}\right)$ varied from 4 to 8 .

\section{Result and discussion}

\subsection{Non-vegetated oblique weir}

The measured data can be used to calculate some dependent flow parameters. The most important one is the discharge 


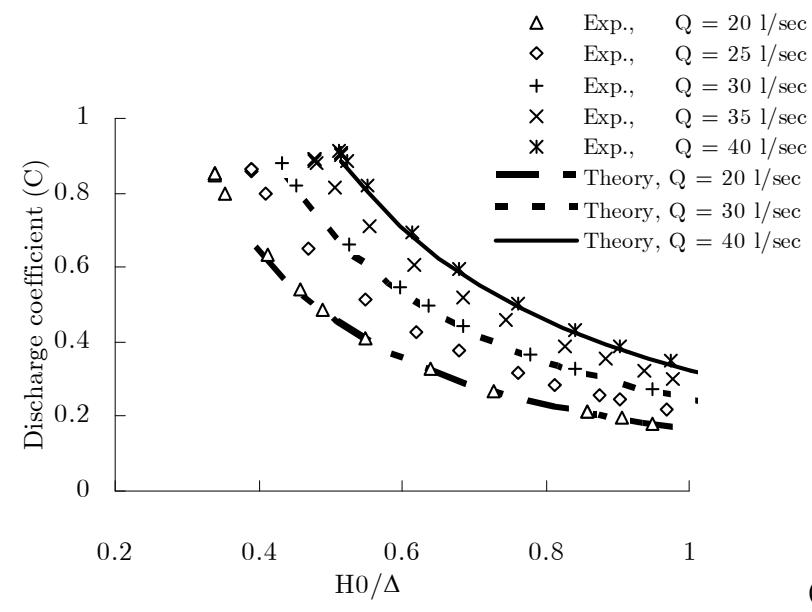

(a)

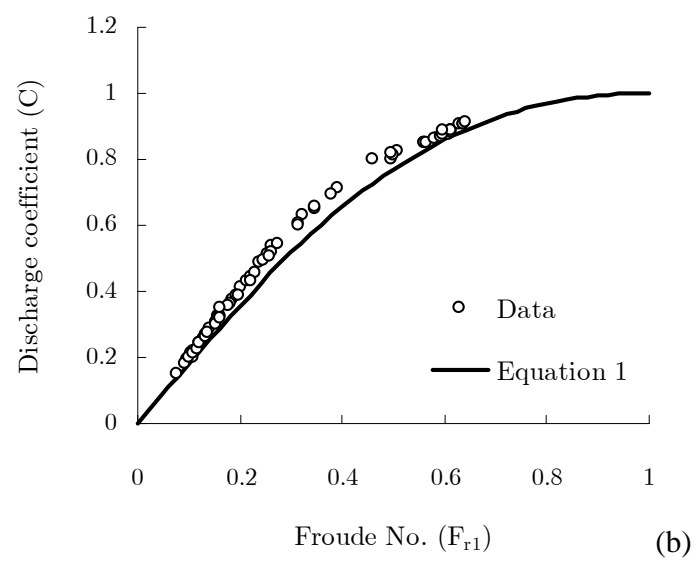

Fig. 11. Discharge coefficient $(C)$ variation versus upstream energy head - non-dimensioned by weir height (a), discharge coefficient variation versus Froude no. on weir crest (b).

coefficient $(C)$ as defined in Eq. (3). The discharge coefficient is plotted against the relative upstream water head $\left(H_{0} / \Delta\right)$ in Fig. 11a.

With a certain discharge, $C$ decreases as the relative upstream water head increases. In the same figure, the right graph shows the variation of discharge coefficient with the Froude number $\left(F r_{1}\right)$ on the weir crest and a comparison with the analytical results (Eq. 1). When the Froude number is low (high submergence flow condition), the loss in water head from the upstream to down stream section is also small.

In Fig. 12 the discharge reduction coefficient $\left(C_{\mathrm{d}}\right)$ is plotted against the submergence for the inclination angle of $45^{\circ}$. The discharge reduction coefficient based on the oblique weir length and based on the channel width $(B)$ is plotted and it is also plotted for the plain perpendicular weir. This figure also presents the discharge reduction coefficient deduced from the Villemonte (1947) relationship $\left(C_{\mathrm{d}}=\sqrt{\left(1-S^{P}\right)}\right)$ using different $p$ values. The graph based on Eq. (5) (Borgei's relation) has been drawn in this figure as well. This figure clearly depicts that the results for Borghei et al. (2003)

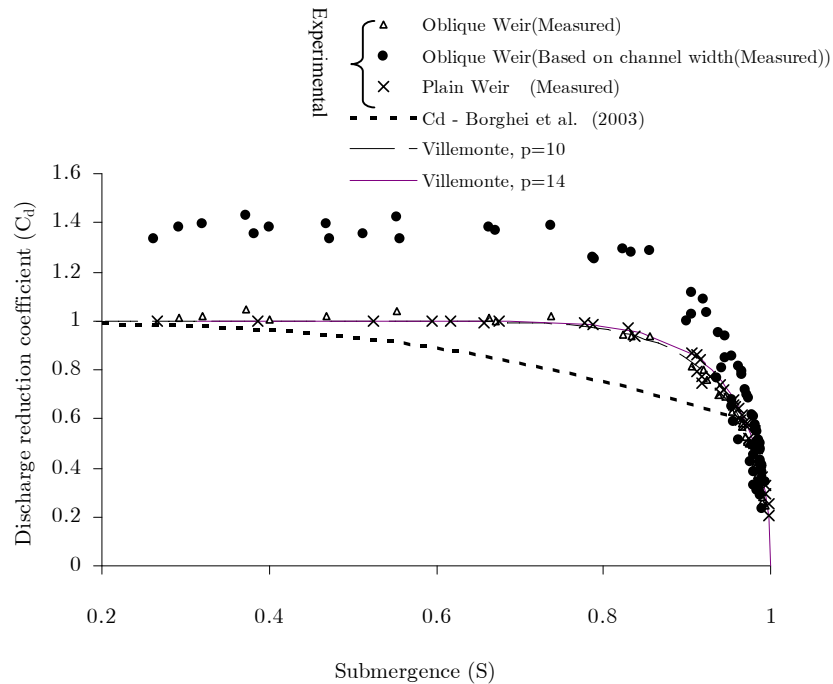

Fig. 12. Discharge reduction coefficient $\left(C_{\mathrm{d}}\right)$ versus submergence, $S$ (angle of obliqueness is $45^{\circ}$ ).

have a significant deviation from the experimental data. The relationship given by Borghei et al. (2003) is highly empirical and also very much dependent on the experimental conditions.

It can be seen from this figure that if the discharge coefficient is calculated based on the weir length, it is the same as for the plain weir. On the other hand, if this is calculated based on the channel width, its value increases by a factor $L / B\left(1.414\right.$ in case of the used oblique angle $\left.\varphi=45^{\circ}\right)$ times the $C_{\mathrm{d}}$ for a plain weir.

\subsection{Comparison of energy head loss and discharge coefficient predicted by the expansion loss form drag model with experimental data for non-vegetated oblique weirs}

Figure 13 shows the comparison between analytical and experimental data for the discharge coefficient from this experiment and those of De Vries (1959) and Tuyen (2006). The results are plotted for the different inclinations of $\varphi=0,45$ and $60^{\circ}$. The analytical results are calculated for dimensionless weir heights $\left(\Delta^{*}\right) 4,6$ and 8 . The discharge coefficient is plotted versus the submergence $\left(H_{2} / H_{0}\right)$. The experimental data for the angle of inclination 0 and $60^{\circ}$ has been taken from De Vries (1959) and Tuyen (2006) for dyke form weirs (upstream and downstream slopes are 1:4). It is clear from the figure that $C$ increases with increasing the inclination due to the increased length of the weir crest which is given as $L=B \cos \varphi$. This limiting value is not measured here, as part of kinetic energy on the upstream side of the weir (related to the parallel velocity component) does not contribute to the discharge. The overall agreement between the analytical results and the experimental results was quite good, showing that the expansion loss form drag model can be applied to 

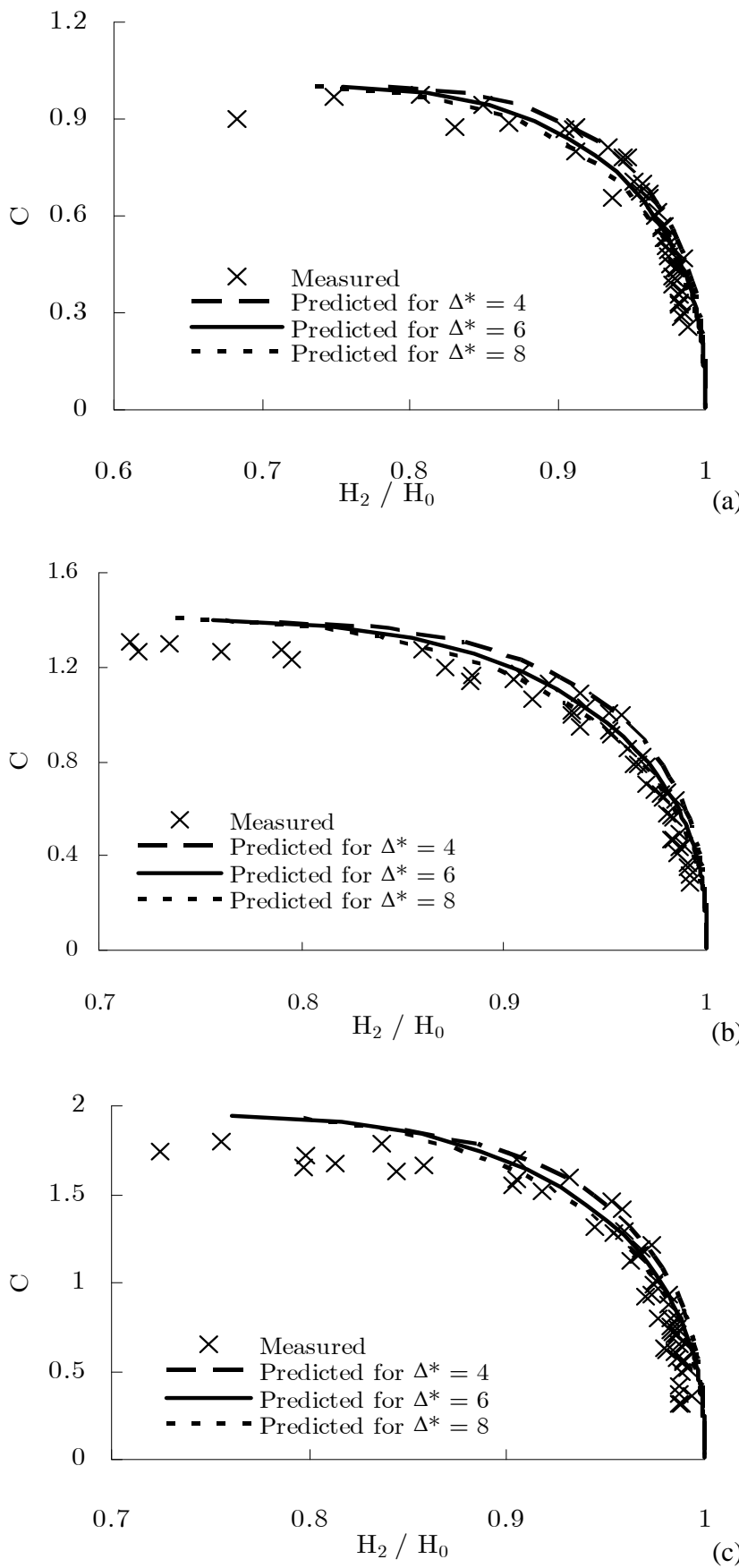

Fig. 13. Discharge coefficients (based on channel width $(B=L \cdot \cos \varphi))$ for different angles of obliqueness, measured (De Vries, 1959; Tuyen, 2006) and predicted data is compared for different downstream water levels; inclination angle $0^{\circ}$ (a), $45^{\circ}$ (b), $60^{\circ}$ (c).

oblique weir-like obstacles considering velocity decomposition as explained in Sect. 3.

Figure 14 shows the comparison of the discharge coefficients which are predicted by the expansion loss form drag model and the experimental data for the different angles of

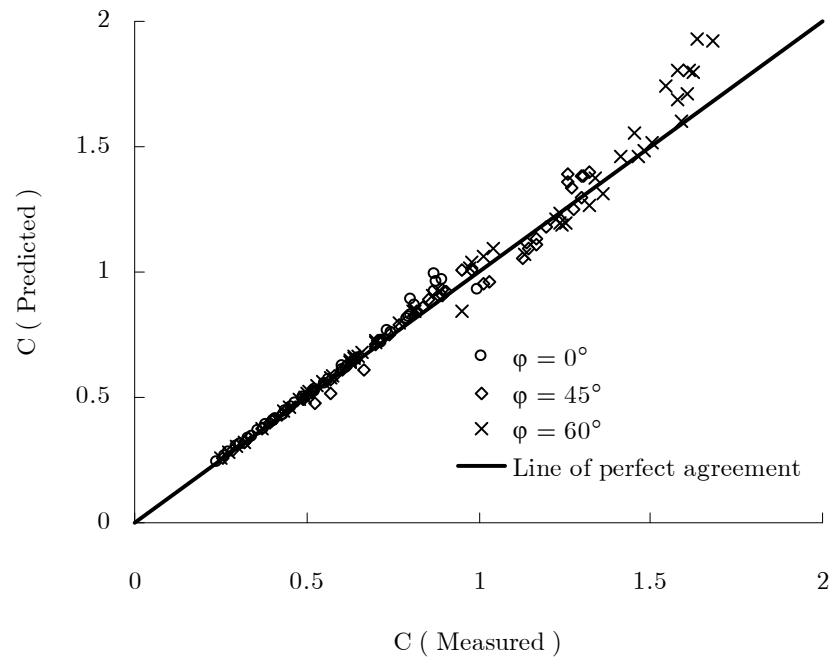

Fig. 14. Comparison of predicted and measured discharge coefficients (based on channel width $B=L \cdot \cos \varphi$ ).

inclination. For the low angle of inclination, the predicted results are more accurate. The results showed a stronger deviation for higher angles of obliqueness due to the effect of the velocity component which is ignored and also due to the strong deflection of the flow and the complex flow structure in the wake of the weir. The mean relative error in the predictions for the obliqueness angle 0,45 and $60^{\circ}$ is 4,7 and $11 \%$, respectively.

Figures 13 and 14 depict significant deviation of predicted discharge coefficients at higher values of $C$ typically for submergence $\leq 0.8$ and $F r \geq 0.6$.

\subsection{Velocity direction on the crest of oblique weirs}

It is assumed in the theoretical analysis that the weir-like obstacle does not affect the parallel velocity component (parallel to the weir crest). As the measurements by Tuyen (2006) show, the velocity components perpendicular and parallel to the weir crest are uniform along the weir length and only show some deviation near the side walls. On the downstream side of the weir, the deflected flow interacts with the sidewalls of the flume and its uniformity is gradually lost, in some cases even giving rise to horizontal flow separation. The above mentioned assumption for the parallel component is valid for the regions where the wall effects are small.

Figure 15 shows the comparison of the analytically computed flow direction (Eq. 8) at the weir crest with measured data (Tuyen, 2006). The results are showing satisfactory agreement between measured and predicted values. Analytical results for flow directions are based on energy conservation at the upstream side of the weir and continuity equation of the flow. The mean relative error for the predicted velocity direction on the weir crest in both cases is $15 \%$. The predicted results are somewhat lower than the measured ones which is partially explained in the discussion of Figs. 13 


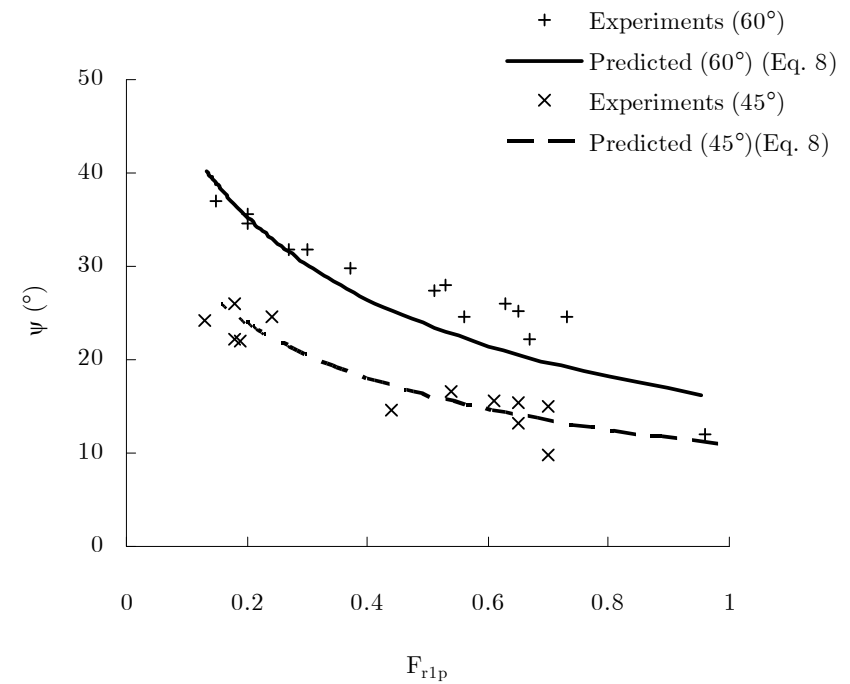

Fig. 15. Flow direction on the weir crest versus Froude number at the centre of the weir crest.

and 14. The experimental results are based on the surface velocities from PTV (particle tracking velocimetry) analyses instead of the average velocities, which is the reason for deviation of data from the theory.

\subsection{Comparison of the energy head loss caused by the vegetated and non-vegetated oblique weirs}

Figure 16 illustrates the comparison of the energy head loss of vegetated and non-vegetated weirs for different discharges. It also shows the analytically predicted results using the expansion loss form drag model discussed in Sect. 3 for vegetated and non-vegetated oblique weirs. It is clear from the figure that the energy head loss increased due to the extra blockage (vegetation blockage) on the weir crest. The vegetation on the weir crest also enhances the turbulence in the flow which increases the energy head loss. The effects of some main hydraulic parameters to the energy head loss can be summarized as follow:

- with the constant discharges, the head loss decreases with the increase of the downstream water head (increase of the submergence);

- with the constant downstream water depth, the higher the discharge the bigger the head loss;

- at the free-flow state, the relationship between downstream water depth and the energy head loss is linear; and

- the extra blockage (25\%) due to pseudo vegetation has significantly enhanced the energy head loss.

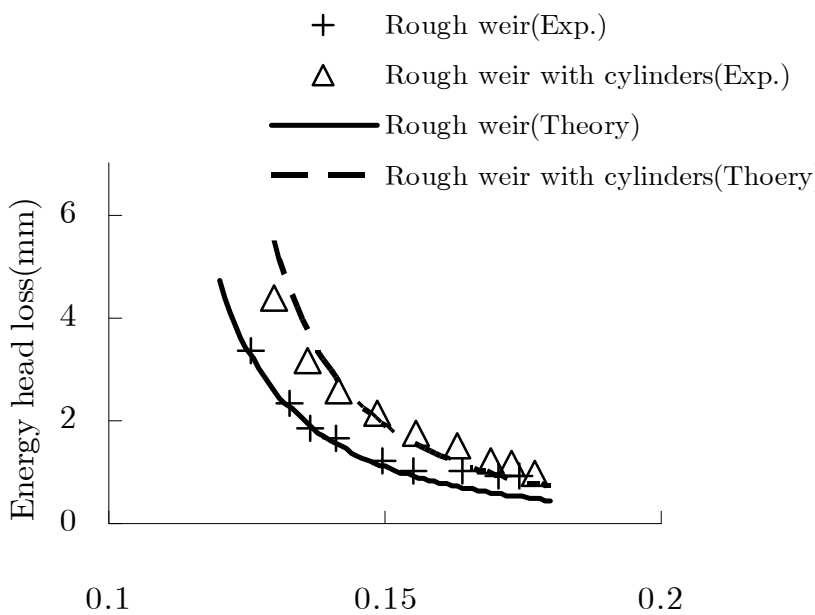

Down stream water $\operatorname{depth}(\mathrm{m})$

(a)

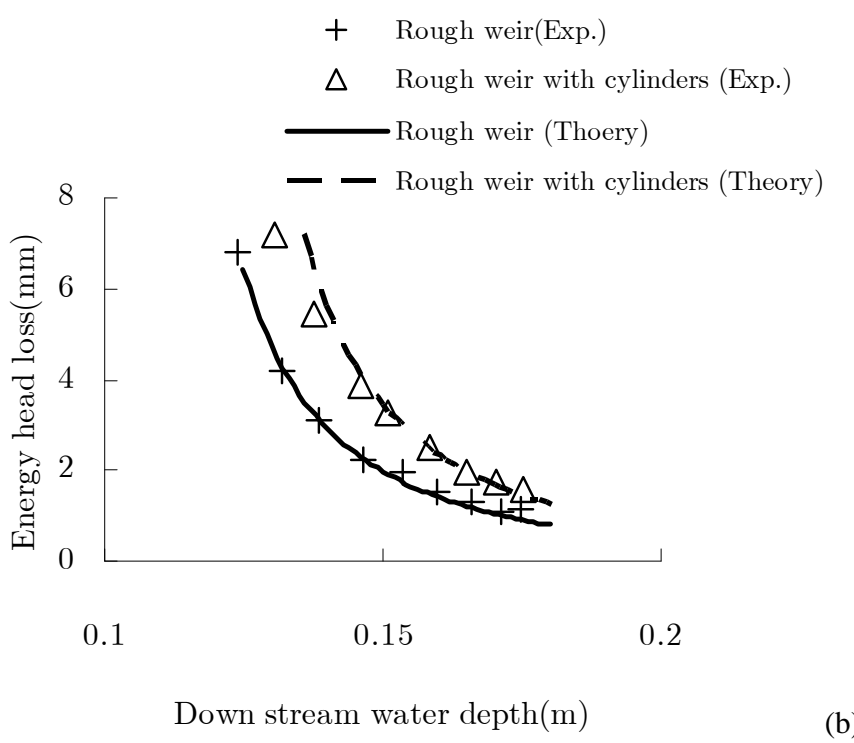

Fig. 16. Comparison of energy head loss for vegetated (submerged vegetation) and non-vegetated oblique weir (Oblique angle, $45^{\circ}$ ), $Q=40 \mathrm{~L} \mathrm{~s}^{-1}$ (a), $Q=30 \mathrm{~L} \mathrm{~s}^{-1}$ (b).

\subsection{Comparison of energy head loss predicted by the expansion loss form drag model with experimental data for vegetated oblique weirs}

The expansion loss form drag model which is developed in Sect. 3 for the vegetated weir has been used to predict the energy head loss caused by the vegetated weir-like obstacles. The weir and vegetation on the crest contract the flow path in vertical and horizontal direction followed by a sudden expansion causing a deceleration region behind the weir. Energy head loss is caused due to this expansion region, having a flow separation region plus additional wake losses in the lee of the vegetation. The expansion loss form drag model is based on the assumption that the velocity component parallel 
to the weir crest remains constant. It is applied to determine the energy head loss caused by the vegetated oblique weir. The vegetation is considered as a horizontal contraction of the flow cross section. In case of submerged vegetation, the shear layer between slow and fast moving water in and above the vegetation also contribute to the energy loss. To include this effect the energy and momentum correction factors $(\alpha$, $\beta$ ) are used with values 1.18 and 1.03 , respectively (Ali and Uijttewaal, 2010). Figure 17 shows the comparison of energy head loss for the vegetated weir between the predicted results by the expansion loss form drag model and the experimental data.

The results predicted by this simple model have an approximate mean relative error of $22 \%$. There is a deviation for the measured results in case of low energy head loss which is due to the inaccuracy of measurements. In case of vegetated oblique weirs the results are under predicted. In this simple theoretical model, the velocity component parallel to the oblique weir is ignored but this component encountered the vegetated elements on the weir crest, that could explain why the model underestimates the energy head loss here. For higher energy head loss, the deviation from the predicted results is due to the surface curvature and the non-hydrostatic pressure which starts to contribute typically for a Froude number higher than 0.6 (Ali and Uijttewaal, 2013).

\section{Conclusions}

Vegetated weir-like obstacles in the floodplain are important features when these are related to determine the flood flow capacity and water levels in order to design embankments. With a simple expansion loss form drag model which is based on principle of energy and momentum conservation, reasonably accurate ( $15 \%$ error) results related to the energy head loss and the flow direction over the weir crest have been obtained.

Some main conclusions that were drawn from this study are listed below:

- The energy dissipation has its maximum value for the case of a hydraulic jump behind weir, and minimum value for the case of completely submerged flow.

- The flow direction changes to an approximately perpendicular orientation in the upstream vicinity and on the weir crest.

- For perfect weir flow conditions the flow was directed almost perpendicular to the weir crest but for high water levels, the flow was less affected and maintained the direction.

- The discharge of an oblique weir is much higher than the discharge of a perpendicular weir with the same channel width because of the higher effective length and a hardly smaller discharge coefficient.

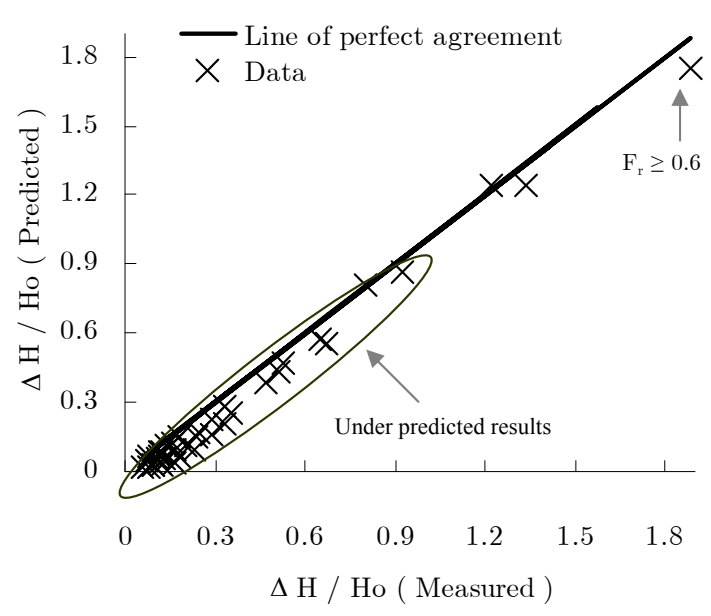

Fig. 17. Comparison of energy head loss (for a weir with vegetation, angle of obliqueness is $\left.45^{\circ}\right), \alpha=1.18$ and $\beta=1.03$.

- The velocity decomposition is a useful step in studying the flow over an oblique weir without vegetation. The velocity component perpendicular to the weir accounts for most of the change in the total velocity, whereas the parallel component stays almost unchanged.

- The higher angles of obliqueness cause greater error in the predicted results due to the ignored parallel velocity component that becomes larger.

- The energy head loss increased due to the extra blockage (vegetation blockage) on the weir crest. Vegetation on the weir crest also enhances the flow turbulence which increases the energy head loss.

- The expansion loss form drag model can be used to predict the discharge coefficient and energy head loss caused by the oblique vegetated obstacles. It is only applicable to submerged flow conditions where the hydrostatic pressure assumption is valid. It gives better results for low angle of obliqueness and low Froude numbers.

\section{Appendix A}

\section{Energy and momentum balance}

Using the assumptions which are discussed in Sect. 3, the energy balance is applied to the upstream region of the weir and it is assumed that there is no energy loss in the contraction region upstream of the weir:

$d_{0}+\alpha_{0} \frac{u_{0}^{2}}{2 g}=\left(d_{1}+\Delta\right)+\alpha_{1} \frac{u_{1}^{2}}{2 g}$,

where $d_{0}, d_{1}, d_{2}$ are water depths, $\alpha$ is the kinetic energy correction coefficients and $u_{0}, u_{1}, u_{2}$ are the depth averaged 
velocities at sections $0,1,2$, respectively. The velocity is decomposed into two components, parallel and perpendicular to the weir axis such that

$u_{0}^{2}=u_{0 \mathrm{p}}^{2}+u_{0 \mathrm{~L}}^{2}, \quad u_{1}^{2}=u_{1 \mathrm{p}}^{2}+u_{1 \mathrm{~L}}^{2}$,

where subscript "p" is for perpendicular and " $L$ " for parallel direction. The continuity equation always holds true for the flow in our case (as stated before).

$Q=u_{0 \mathrm{P}} d_{0} L=u_{1 \mathrm{p}} d_{1} L$ and $q_{\mathrm{L}}=u_{0 \mathrm{p}} d_{0}=u_{1 \mathrm{p}} d_{1}=u_{2 \mathrm{p}} d_{2}$

where $Q$ is the total discharge of the flow cross section, $L$ $(\mathrm{m})$ is the length of the oblique weir and can be calculated as $L=B / \cos \varphi(B$ is the channel width, Fig. 3). The assumption made here is that the velocity component parallel to the weir crest remains constant in the area of investigation so $u_{0 \mathrm{~L}}=u_{1 \mathrm{~L}}$. Using the continuity equation (Eq. A3), the energy balance (Eq. A4) can be written as

$$
\begin{aligned}
d_{0}+\alpha_{0} \frac{u_{0 \mathrm{P}}^{2}}{2 g} & =\left(d_{1}+\Delta\right)+\alpha_{1} \frac{u_{1 \mathrm{P}}^{2}}{2 g} \text { or } d_{0}+\alpha_{0} \frac{q_{\mathrm{L}}^{2}}{2 g d_{0}^{2}} \\
& =\left(d_{1}+\Delta\right)+\alpha_{1} \frac{q_{\mathrm{L}}^{2}}{2 g d_{1}^{2}},
\end{aligned}
$$

where $q_{\mathrm{L}}$ is the specific discharge, $\Delta$ is the weir height and $g$ is the gravitational acceleration. All lengths can be nondimensionalized by the critical water depth at the section 1 . Defining the Froude number as (Chanson, 1999; Jain, 2001) $F r_{1}=\frac{u_{1 \mathrm{p}}}{\sqrt{g d_{1}}}=\frac{q_{\mathrm{L}}}{d_{1} \sqrt{g d_{1}}}$, it gives the critical depth $\left(d_{\mathrm{cr} 1}\right)$ above the weir crest:

$d_{\mathrm{cr} 1}=\sqrt[3]{q_{\mathrm{L}}^{2} / g}$.

This approach simplifies the equations and reveals that the dimensionless weir height $\left(\Delta^{*}\right)$ is the only parameter in the problem (Eq. A5). The dimensionless energy conservation between section 0 and 1 is written as

$d_{0}^{* 3}-\left(d_{1}^{*}+\Delta^{*}+\alpha_{1} \frac{1}{2 d_{1}^{* 2}}\right) d_{0}^{* 2}+\frac{1}{2} \alpha_{0}=0$.

At the downstream side of weir, the momentum conservation assuming a hydrostatic pressure distribution and ideal flow (no friction losses) applied to sections 1 and 2 yields:

$\frac{1}{2} \rho g\left(d_{1}+\Delta\right)^{2}-\frac{1}{2} \rho g d_{2}^{2}=\rho q\left(\beta_{2} u_{2}-\beta_{1} u_{1}\right)$,

where $\beta$ is the dimensionless momentum correction coefficient and $\rho\left(\mathrm{kg} \mathrm{m}^{-3}\right)$ is the density of water. Velocity is again decomposed into two components as above in the case of the energy balance upstream of the weir.

$u_{2}^{2}=u_{2 \mathrm{p}}^{2}+u_{2 \mathrm{~L}}^{2}, \quad u_{1}^{2}=u_{1 \mathrm{p}}^{2}+u_{1 \mathrm{~L}}^{2}$

Assuming the constant flow rate parallel to the weir, Eq. (A6) can be written as

$\frac{1}{2} \rho g\left(d_{1}+\Delta\right)^{2}-\frac{1}{2} \rho g d_{2}^{2}=\rho q_{\mathrm{L}}\left(\beta_{2} u_{2 \mathrm{p}}-\beta_{1} u_{1 \mathrm{p}}\right)$.
The dimensionless momentum conservation between sections 1 and 2 can be written as (van Rijn, 1990)

$d_{1}^{* 3}+2 \Delta^{*} d_{1}^{* 2}+\left(\Delta^{* 2}-d_{2}^{* 2}-\beta_{2} \frac{2}{d_{2}^{*}}\right) d_{1}^{*}+2 \beta_{1}=0$.

\section{Appendix B}

\section{Flow direction}

A relation between the angle of obliqueness, the flow direction above the weir crest can be written as given below;

$\tan \varphi=\left(\frac{u_{0 \mathrm{p}}}{u_{0 \mathrm{~L}}}\right), \quad \tan \psi=\left(\frac{u_{0 \mathrm{p}}}{u_{0 \mathrm{~L}}}\right) \Rightarrow \frac{\tan \varphi}{\tan \psi}=\frac{u_{1 \mathrm{p}}}{u_{0 \mathrm{p}}}$.

The continuity equation of flow leads to $\frac{u_{1 \mathrm{p}}}{u_{0 \mathrm{p}}}=\frac{d_{0}}{d_{1}}$ and the specific discharge can be written as

$q_{\mathrm{L} 1}=F r_{1 \mathrm{p}} \sqrt{g} d_{1}^{\frac{3}{2}}, \quad q_{\mathrm{L} 0}=F r_{0 \mathrm{p}} \sqrt{g} d_{0}^{\frac{3}{2}} \Rightarrow \frac{F r_{1 \mathrm{p}}}{F r_{0 \mathrm{p}}}=\left(\frac{d_{0}}{d_{1}}\right)^{\frac{3}{2}}$.

Using Eqs. (B1) and (B2), the relation between $\psi, \varphi$ and flow conditions reads

$\frac{\tan \psi}{\tan \varphi}=\left(\frac{F r_{0 \mathrm{p}}}{F r_{1 \mathrm{p}}}\right)^{\frac{2}{3}}$

Acknowledgements. Authors are indebted to acknowledge the Higher Education Commission of Pakistan (HEC), Ministry of Transport, Public works and water management (RWS), the Netherlands and Deltares Delft, the Netherlands, for their financial contribution to this work. We would like to thank Robert Jan Labeur and Arjan Sieben for meaningful suggestions.

Edited by: G. Di Baldassarre

\section{References}

Aichel, O. G.: Abflusszahlen fur schiefe Wehre (Discharge ratios for oblique weirs), Z. VDI, 95, 26-27, 1953.

Ali, S. and Uijttewaal, W. S. J.: Form drag due to vegetated weirlike obstacles interpreted as expansion loss, 33rd IAHR world congress, Vancouver, Canada, 139-146, 2009.

Ali, S. and Uijttewaal, W. S. J.: Flow resistance of vegetated weirlike obstacles during high water stages, Proceedings of river flow, Braunschweig, Germany, 293-299, 2010.

Ali, S. and Uijttewaal, W. S. J.: Flow resistance of vegetated weirlike obstacles during high water stages, J. Hydraul. Eng., 139, 325-330, 2013.

Azimi, A. H. and Rajaratnam, N.: Discharge characteristics of weirs of finite crest length, J. Hydraul. Eng., 135, 1081-1085, 2009.

Brater, E. F. and King, H. W.: Handbook of hydraulics, 6th Edn., McGraw-Hill, New York, 1976. 
Borghei, S. M., Vatannia, Z., Ghodsian, M., and Jalili, M. R.: Oblique rectangular sharp-crested weir, Water Mar. Eng., 156, 185-191, 2003.

Borghei, S. M., Kabiri-Samani, A. R., and Nekoee, N.: Oblique weir equation using incomplete self- similarity, Can. J. Civil Eng., 33, 1241-1250, 2006.

Bos, M. G.: Discharge measurement structures, 3rd Edn., ILRI, Wageningen, the Netherlands, 1989.

Chanson, H.: The Hydraulics of open channel flow, Willey, New York, 1999.

Chaudhry, M. H.: Open Channel flow, Prentice-Hall of India, New Delhi, 1994.

Chow, V. T.: Open channel hydraulics, McGraw-Hill, Tokyo, 1959.

Colebrook, C. F.: Turbulent flow in pipes with particular reference to the transition region between the smooth and rough pipe laws, J. Inst. Civ. Eng. Lond., 11, 133-156, 1939.

De Vries, M.: Scheef aangestrooomde overlaten, Rapport model onderzoek WL-Delft Hydraulics, Delft, 1959.

Engelund, F.: Hydraulic resistance of alluvial streams, J. Hydraul. Eng. Div., 92, 315-326, 1966.

Fritz, H. M. and Hager, W. H.: Hydraulics of Embankment Weirs, J. Hydraul. Eng., 124, 963-971, 1998.

Govida Rao, N. S. and Muralidhar, D.: Discharge characteristics of Weirs of finite crest length, La Houille Blanche, 5, 537-545, 1963.

Hager, W. H.: Breitkroniger Überfall, Wasser, Energie, Luft, 86 Jahrgang, Heft 11/12, Baden, 363-369, 1994.

Hager, W. H.: Die Verlustbeiwerte in Rohren und Gerinnen, 76 Jahrgang, Heft 11/12, Wasser, Energie, Luft - eau, Energie, air, Baden, 253-261, 1993.

Jain, S. C.: Open channel flow, John Wiley and Sons, New York, 2001.

Kandaswamy, P. K. and Rouse, H.: Characteristics of flow over terminal weirs and sills, J. Hydraul. Div.-ASCE, 83, 1-13, 1957.

Karim, F.: Bed-form geometry in sand bed-flows, J. Hydraul. Eng., 125, 1253-1261, 1999.
Kindsvater, C. E. and Carter, R. W. C.: Discharge Characteristics of Rectangular Thin-Plate Weirs, J. Hydraul. Div., 83, 1-36, 1957.

Munson, B. R., Young, D. F., and Okiishi, T. H.: Fundamentals of fluid mechanics, 4th Edn., John Wiley \& Sons, Inc., Hobokin, 2002.

Ramamurarthy, A. S., Tim, U. S., and Rao, M. J.: Flow over sharp crested plate weirs, J. Irrig. Drain. Eng., 113, 163-172, 1987.

Rehbock, T.: Discussion of precise weir measurements, T. ASCE, 93, 1143-1162, 1929.

Rouse, H.: Discharge characteristics of the free overfall, Civil Eng.ASCE, 6, 257-260, 1936.

Sargison, J. E. and Percy, A.: Hydraulics of broad-crested weirs with varying side slopes, J. Irrig. Drain. Eng.-ASCE, 135, 115118, 2009.

Swamee, P. K.: Generalized Rectangular Weir equations, J. Hydraul. Eng.-ASCE, 14, 945-949, 1988.

Tuyen, N. B.: Flow over oblique weirs, MSc Thesis, TU Delft, Delft, the Netherlands, 2006.

Tuyen, N. B.: Influences of the oblique Obstacles to the flow, JapanVietnam Estuary Workshop, Hochiminh, Vitenam, 2007.

van der Mark, C. F.: A Semi-Analytical Model for form drag of river bed forms, Ph.D. thesis, University of Twente, Twente, the Netherlands, 2009.

van Rijn, L. C.: Principles of fluid flow and surface waves in rivers, estuaries, seas and oceans, Aqua Publications, Blokzijl, the Netherlands, 1990.

Villemonte, J. R.: Submerged Weir Discharge Studies, Eng. News Record, 193, 866-869, 1947.

Wols, B. A, Uijttewaal, W. S. J., Labeur, R. J., and Stelling, G.: Rapidly varying flow over oblique weirs, Proceedings of the 7th Int. Conf. On Hydroscience and Engineering (ICHE-2006), 13 September, Philadelphia, USA, 1-13, 2006.

$\mathrm{Wu}, \mathrm{S}$. and Rajaratnam, N.: Submerged flow regimes of rectangular sharp-crested weirs, J. Hydraul. Eng.-ASCE, 122, 412-414, 1996.

Yalin, M. S.: On the average velocity of flow over a mobile bed, La Houille Blanche, 1, 45-53, 1964. 